\title{
Randomised controlled trial of infantile colic treated with chiropractic spinal manipulation
}

\author{
E Olafsdottir, S Forshei, G Fluge, T Markestad
}

\begin{abstract}
Aims-To investigate the efficacy of chiropractic spinal manipulation in the management of infantile colic.

Methods-One hundred infants with typical colicky pain were recruited to a randomised, blinded, placebo controlled clinical trial.

Results-Nine infants were excluded because inclusion criteria were not met, and five dropped out, leaving 86 who completed the study. There was no significant effect of chiropractic spinal manipulation. Thirty two of 46 infants in the treatment group $(69.9 \%)$, and 24 of 40 in the control group $(60.0 \%)$, showed some degree of improvement.

Conclusion-Chiropractic spinal manipulation is no more effective than placebo in the treatment of infantile colic. This study emphasises the need for placebo controlled and blinded studies when investigating alternative methods to treat unpredictable conditions such as infantile colic.

(Arch Dis Child 2001;84:138-141)
\end{abstract}

Keywords: infantile colic; crying; spinal manipulation; chiropractic treatment

Infantile colic presents during the first three months of life as excessive crying in an otherwise healthy, thriving infant who has a normal weight gain. Most studies on infantile colic apply the diagnostic criteria of Wessel and colleagues, ${ }^{1}$ which define infantile colic as paroxysms of uncontrollable crying or fussing in a healthy infant less than 3 months of age; duration of crying is more than three hours per day and more than three days per week for more than three weeks. Typically the crying in infantile colic starts at the same time each day and is most intense in the afternoon, evening, and at night. $^{2}$

Studies of crying in western infants have

Department of Paediatrics, University of Bergen, 5021

Bergen, Norway

E Olafsdottir

G Fluge

T Markestad

Private Practice of Chiropractic, Bergen, Norway

$S$ Forshei

Correspondence to:

Dr Olafsdottir

eola@haukeland.no

Accepted 8 September 2000

shown that there is an expected increase in the amount of crying from birth to reach a peak around 6 weeks of age. Thereafter a decline is observed until 12 weeks of age. There is an evening clustering of crying in the first three months of life; this pattern of crying is identical to the pattern in infants with colic. ${ }^{3-5}$

A multitude of approaches to treatment reflects the fact that the mechanisms underlying infantile colic are not known. The main hypotheses postulate that crying is a result of behavioural disturbances or organic pain. ${ }^{6-10}$

Some infants with colic respond favourably to a cow's milk free diet for the mothers who breast feed, or to cow's milk free formula in formula fed infants. ${ }^{11-14}$

Oral sucrose has an analgesic effect in newborn infants ${ }^{15}$ and has been shown to have a significant ameliorating effect on infant colic. ${ }^{16}$ The anticholinergic drugs dicyclomine hydrochloride and dicycloverine have been effective in treating colic, ${ }^{17}$ but are no longer used because of serious side effects. ${ }^{18}$ Simethicone is often used, but controlled trials have failed to show benefits. ${ }^{19}$

In Scandinavia, chiropractic treatment is frequently used in infantile colic and both parents and chiropractors have reported a favourable effect. ${ }^{20}{ }^{21}$ However, until recently the effect of this treatment modality has been impossible to evaluate because of lack of properly performed controlled studies. In a study by Klougart et al, chiropractic treatment seemed to have a positive effect, but the trial did not include a control group. ${ }^{21}$ A recent randomised controlled clinical trial with a blinded observer concluded that spinal manipulation had a positive short term effect, measured as a reduction in hours of crying. ${ }^{22}$

The purpose of the present study was to evaluate the efficacy of chiropractic spinal manipulation in the treatment of infantile colic in a randomised, blinded, and placebo controlled clinical trial.

Subjects and methods

From April 1998 to December 1999, 100 colicky infants were recruited in Bergen from public health care clinics, the paediatric outpatient clinic at the University Hospital, general practitioners, chiropractors, and from direct referrals from parents who were informed about the project at the maternity units in Bergen and by the media.

Before entering the study, all the following criteria had to be met.

(1) Typical infantile colic as defined by Wessel et al (minimum of three hours of crying per day, three days per week for the last three weeks). ${ }^{1}$ The infants were aged 3-9 weeks.

(2) No benefit from cow's milk free diet to the mother for four days in breast fed infants, or casein hydrolysed formula for four days in bottle fed infants.

(3) No signs of lactose intolerance, as examined by $\mathrm{pH}$ and reducing substances in the stools.

(4) Insufficient effect of sucrose on crying.

(5) No previous chiropractic treatment.

(6) Appropriate gain in weight, length, and head circumference and a normal psychomotor development on paediatric physical examination. 
Table 1 Characteristics of infants in the treatment and control groups

\begin{tabular}{|c|c|c|c|}
\hline & $\begin{array}{l}\text { Treatment group } \\
n=46\end{array}$ & $\begin{array}{l}\text { Controls } \\
n=40\end{array}$ & $p$ value \\
\hline Boys/girls & $20 / 26$ & $27 / 13$ & 0.031 \\
\hline Birth weight $(\mathrm{g})$ & $3687(405)$ & $3695(571)$ & 0.943 \\
\hline Length at birth $(\mathrm{cm})$ & $50.5(1.8)$ & $50.5(2.3)$ & 0.988 \\
\hline Weight at study (g) & $4735(551)$ & $4884(699)$ & 0.287 \\
\hline Length at study (cm) & $56.3(1.9)$ & $56.7(2.4)$ & 0.469 \\
\hline Head circumference at study $(\mathrm{cm})$ & $38(1.3)$ & $38.3(1.5)$ & 0.429 \\
\hline Duration of colic (wk) & $3.6(1.5)$ & $4.3(1.9)$ & 0.062 \\
\hline Crying per day (h) & $4.9(1.7)$ & $5.3(2.6)$ & 0.402 \\
\hline Consistent diurnal pattern of crying & $39(88.6 \%)$ & $34(85.0 \%)$ & 0.629 \\
\hline Purely breast fed & $43(93.5 \%)$ & $32(80.0 \%)$ & 0.073 \\
\hline Partly breast fed & $3(6.5 \%)$ & $5(12.5 \%)$ & 0.357 \\
\hline Bottle fed (casein hydrolysed formula) & $0(0.0 \%)$ & $3(7.5 \%)$ & 0.083 \\
\hline \multicolumn{4}{|l|}{ Previous treatment } \\
\hline Defoaming agent & $24(52.2 \%)$ & $21(52.5 \%)$ & 0.781 \\
\hline Music/sound & $28(60.9 \%)$ & $18(45.0 \%)$ & 0.180 \\
\hline Sucrose & $46(100 \%)$ & $40(100 \%)$ & \\
\hline Normal vaginal delivery & $30 \star(75 \%)$ & $24 \dagger(77.4 \%)$ & 0.815 \\
\hline Pathological delivery & $10^{\star}(25 \%)$ & $7+(22.6 \%)$ & 0.815 \\
\hline Vacuum extraction & $0 \star(0.0 \%)$ & $3+(9.7 \%)$ & 0.083 \\
\hline Instrumental delivery & $5^{\star}(12.5 \%)$ & $1+(3.2 \%)$ & 0.140 \\
\hline Caesarean section & $5^{\star}(12.5 \%)$ & $3+(9.7 \%)$ & 0.710 \\
\hline Siblings & $27(58.7 \%)$ & $25(62.5 \%)$ & 0.722 \\
\hline Siblings with colic & $19 / 27 \ddagger(70.4 \%)$ & $16 / 25 \ddagger(64 \%)$ & 0.633 \\
\hline Mother smokes & $5(10.9 \%)$ & $9(22.5 \%)$ & 0.157 \\
\hline Father smokes & $13(28.3 \%)$ & $10(25.6 \%)$ & 0.789 \\
\hline Single parent family & $6(13 \%)$ & $3(7.5 \%)$ & 0.400 \\
\hline Maternal age (y) & $31.0(5.6)$ & $31.1(6.3)$ & 0.910 \\
\hline Mother's education $>12 \mathrm{y}$ & $39(84.8 \%)$ & $27(67.5 \%)$ & 0.065 \\
\hline Father's education $>12 \mathrm{y}$ & $31(67.4 \%)$ & $22(55.0 \%)$ & 0.246 \\
\hline
\end{tabular}

Results presented as absolute figures or mean values (SD) and (percentage of total); $\mathrm{p}$ values calculated by Fischer's exact test or Student's $t$ test.

${ }^{\star}$ Known for 40 infants; †known for 31 infants; łnumber of infants with siblings.

(7) Born at term with a birth weight of more than $2500 \mathrm{~g}$.

(8) Written informed consent from the parents before entering the study.

The parents were given written information about the study, and were interviewed by one of the investigators (EO). They were asked to keep a 24 hour diary of the infant's crying. The registration started two days before their first visit, and continued until the last visit at the hospital.

At the first visit the infant was randomised (sealed envelopes) to whether spinal manipulation should be given or not. At each visit the parents described the effect of the last visit on a scale of five categories- "getting worse", "no improvement", "some improvement", "marked improvement", "completely well"which were defined as the main outcome measure. One paediatrician (EO) was in contact with all the parents at each visit and filled in the scoring system. Neither doctor nor parents knew whether the infant received treatment or not. A nurse brought the infant to the chiropractor. The infants who did not get spinal manipulation were just held by the nurse for 10 minutes (the approximate time of treatment) after being partially undressed in a similar way as treated infants. In the treatment group the chiropractor palpated the infant's spinal articulations with respect to areas of dysfunction. Dysfunctional articulations were manipulated and mobilised using light fingertip pressure. Before commencing the study the method of chiropractic treatment was agreed by a reference group of 14 chiropractors. The treatment was given three times, at intervals of two to five days, for a period of eight days.

At the repeated visits the infant was examined clinically, and the parents received counselling and support on feeding, baby care, and
Table 2 Outcome according to symptom score 8-14 days after the last visit during the study

\begin{tabular}{lcc}
\hline Symptom score & $\begin{array}{l}\text { Treatment group } \\
(n=46)\end{array}$ & $\begin{array}{l}\text { Controls } \\
(n=40)\end{array}$ \\
\hline 1 = getting worse & 5 & 6 \\
2 = no improvement & 9 & 10 \\
$3=$ some improvement & 13 & 7 \\
$4=$ marked improvement & 10 & 8 \\
$5=$ completely well & 9 & 9 \\
\hline
\end{tabular}

family interaction as usually given to families with colicky infants. After the last visit there was an observation period of eight to 14 days. At the end of the observation period, the parents were contacted by telephone and interviewed according to the same categorical scale, by a blinded observer.

The study was approved by the regional committee on medical research ethics.

\section{STATISTICAL METHODS}

All statistic calculations and graphic designs were performed using commercially available software (SPSS for Windows, version 9.0.0, 1998, SPSS Inc., Chicago, Illinois).

Categorical variables with responses on a nominal scale were analysed with Fischer's two tailed exact test; ordinal variables were analysed with the Mann-Whitney test. The amount of crying from the infants' crying diaries (mean group differences) were analysed with Student's $t$ test. Two tailed $\mathrm{p}$ values were employed, and a $\mathrm{p}$ value of less than 0.05 was considered significant; 95\% confidence intervals (CI) and relative risks (RR) were given whenever appropriate.

\section{Results}

One hundred infants were recruited to the trial and randomised to either receive treatment with spinal manipulation or not. Of these 100 infants, nine were excluded because of transient lactose intolerance $(n=6)$, hypogalactia $(n=2)$, or not fulfilling Wessel's criteria when interviewed on the second visit $(n=1)$. There were five dropouts: four did not come to the second visit (one in the treatment group and three in the control group), and one dropped out later from the control group.

All 86 infants who completed the study were born at term. They were healthy, had gained appropriately in weight, length, and head circumference, and psychomotor development was normal (table 1). The mean duration of colic was 3.9 weeks, and most of the infants had a consistent diurnal pattern of crying $(86.9 \%)$. Many of the parents had tried various treatments before entry to the trial. There were no differences between the groups treated and not treated with regard to entry data, except for number of boys and girls: there were fewer girls in the control group than in the treatment group $(\mathrm{p}=0.031$; table 1$)$.

There was no difference in outcome between those treated and not treated when analysed according to the parents' report (MannWhitney test, $\mathrm{p}=0.743$; table 2 ), or according to hours of crying based on the diaries for 42 infants in the treatment group and 33 infants in the control group (Student's $t$ test, $\mathrm{p}=0.982$; 
Table 3 Hours of crying before and during the treatment period of eight days for those infants whose parents managed to complete the diary appropriately

\begin{tabular}{llll}
\hline & Treatment group & Controls & p value \\
\hline Pretreatment & $5.1(3.0)(\mathrm{n}=41)$ & $5.4(3.2)(\mathrm{n}=31)$ & 0.612 \\
At first visit & $4.2(2.7)(\mathrm{n}=42)$ & $3.9(2.5)(\mathrm{n}=33)$ & 0.612 \\
At second visit (day 3-6) & $3.4(2.7)(\mathrm{n}=42)$ & $3.2(2.5)(\mathrm{n}=33)$ & 0.602 \\
At third visit (day 8) & $3.1(2.7)(\mathrm{n}=42)$ & $3.1(2.7)(\mathrm{n}=33)$ & 0.982 \\
\hline
\end{tabular}

Results expressed as mean (SD); p values calculated by Student's $t$ test.

table 3). In both the treatment and control group there was a reduction in crying hours per day during the study, from a mean of 5.1 to 3.1 hours per day in the treatment group (41 diaries) and from a mean of 5.4 to 3.1 hours per day in the control group (31 diaries; table $3)$. In the treatment group, 32 of 46 infants $(69.9 \%)$ showed some degree of improvement according to the parents' report, whereas in the control group 24 of 40 infants $(60.0 \%)$ improved. The difference is not statistically significant (Ficher's exact test, $\mathrm{p}=0.374$ ).

When analysing data according to "intention to treat" to take into account the infants that dropped out from the study, we found no significant difference between the groups on the parent's report, when using either Fischer's test $(p=0.656)$ or the Mann-Whitney test $(\mathrm{p}=0.861)$.

\section{Discussion}

This is the first study that we are aware of, which investigates the effect of chiropractic spinal manipulation in the treatment of infantile colic in a randomised, blinded, placebo controlled clinical trial. In addition to a blinded observer, the parents were blinded as well and did not know whether the infant received treatment with spinal manipulation or not.

In our study we used the parents' final scoring on a scale of $1-5$ as a main measure of outcome. Applying the Mann-Whitney test there was no significant difference between the treatment and the placebo group. We also used a crying diary before and during the study in most of the infants; both groups showed a reduction in hours of crying per day during the study, but again there was no significant difference between the treated group and the control group.

As reported in previous, controlled studies, our study shows a strong placebo effect, and also an effect of counselling and support to the parents of colicky infants. ${ }^{23} 24$

One controlled study that validated spinal manipulation as a treatment of infantile colic has been published previously. ${ }^{22}$ It showed a significant difference between hours of crying per day in two groups of infants, one treated with spinal manipulation and the other with dimethicone. The reduction in hours of crying from pretreatment to days $8-11$, was 2.7 hours versus 1.0 hour respectively in the two groups. Although this study was randomised and controlled with a blinded observer, the parents were not blinded, and there is thus a possibility for bias. The parents of infants in the manipulation group might have had higher expectations about a cure for their infants than parents of infants who were given dimethicone. In pre- vious studies this drug has shown no benefits when compared to placebo treatment. ${ }^{19}$

In our study all infants were treated by the same chiropractor, who has treated colicky infants with spinal manipulation for many years. The infants and their families were seen by the same doctor and nurse. In order to ensure general agreement, the method of chiropractic treatment was agreed by a reference group of 14 chiropractors before commencing the study. The type of spinal manipulation used in this study was a form of modified fingertip mobilisation; a very light manipulation was performed. This procedure is somewhat different from the manipulative procedures commonly employed by chiropractors when treating adults. Characteristically a controlled force is delivered to spinal joints in a specific direction with high velocity, often accompanied by joint "crack" or vacuum phenomenon. ${ }^{25}$ In this study the typical joint "cracks" were not heard in any of the infants. Spinal manipulation is commonly used in the treatment of back and neck disorders, ${ }^{26}$ but it is controversial whether this treatment has any effect on other disorders, especially in children. ${ }^{27} 28$

Entry data for infants in our study showed a significant difference in the number of girls and boys in the groups, with fewer girls in the control than in the treatment group. This finding should not influence the results of our study as previous studies on infantile colic have not shown any sexual predilection. ${ }^{29-31}$

We adhered strictly to the inclusion criteria, and excluded those children with colic that responded favourably to a cow's milk free diet in the mothers who breast fed their infants or cow's milk free formula in formula fed infants. Studies have shown that some infants benefit from this change in their diet. ${ }^{11-14}$

It is reasonable to expect that infants with colic who responded to general measures such as guidance and sugar water were not referred to the study. Sugar water was introduced in this area in $1997^{16}$ and is widely used.

In conclusion, our findings indicate that there are no benefits from treating infantile colic with chiropractic spinal manipulation. Improvement occurred in both the treatment and control groups. This may reflect an effect of general counselling and support from the professional team or a natural spontaneous improvement as a result of increasing age. The study emphasises the need to investigate similar alternative methods of treatment by placebo controlled and blinded studies in order to document whether these treatment regimens are effective or not. This is important in order to establish appropriate advice and counselling to parents of colicky infants, and as a cost-benefit analysis of the treatments used in our society.

The study was supported by the Norwegian Research Council. We thank Mette Lawlor for nursing assistance in the study. We are grateful to the families that took part.

1 Wessel MA, Cobb JC, Jackson ES, Harris GS, Detwiler AC. Paroxysmal fussing in infancy, sometimes called "colic". Pediatrics 1954;14:421-34.

2 Illingsworth RS. "Three months' colic". Arch Dis Child 1954;29:165-74. 
3 St James-Roberts I, Halil T. Infant crying in the first year: normal community and clinical findings. 7 Child Psychol normal community and clinic

4 Brazelton TB. Crying in infancy. Pediatrics 1962;29:579-88.

5 Hunziker UA, Barr RG. Increased carrying reduces infant crying: a randomized controlled trial. Pediatrics 1986;77: 641-8

6 Barr RG, Rotman A, Yaremko J, Leduc D, Francoeur TE. The crying of infants with colic: a controlled empirical description. Pediatrics 1992;90:14-21.

7 St James-Roberts I, Conroy S, Wilsher K. Bases for maternal perceptions of infant crying and colic behavior. Arch Dis Child 1996;75:375-84.

8 Miller AR, Barr RG. Infantile colic. Is it a gut issue? Pediatr Clin North Am 1991;38:1407-23.

9 Illingsworth RS. Infantile colic revisited. Arch Dis Child 1985;60:981-5.

10 Lindberg T. Infantile colic and small intestinal function: a nutritional problem? Acta Pediatr 1999;88(suppl):58-60.

11 Lothe L, Lindberg T. Cow's milk whey protein elicts symptoms of infantile colic in colicky formula-fed infants: a double-blind crossover study. Pediatrics 1989;83:262-6.

12 Hill DJ, Hudson IL, Sheffield LJ, Shelton MJ, Menahem S, Hosking CS. A low allergen diet is a significant intervention in infantile colic: results of community-based study. $\mathcal{F}$ Allergy Clin Immunol 1995;96:886-92.

13 Forsyth BWC. Colic and the effect of changing formulas: a double-blind, multiple-crossover study. $f$ Pediatr 1989;115: 521-6.

14 Hill DJ, Hosking CS. Infantile colic and food hypersensitivity. 7 Pediatr Gastroenterol Nutr 2000;30:S67-S76.

15 Haouari N, Wood C, Griffith G, Levene M. The analgesic effect of sucrose in full term infants: a randomised controlled trial. BMF 1995;310:1498-500.

16 Markestad T. Use of sucrose as a treatment for infant colic. Arch Dis Child 1997;76:1-2.

17 Grunseit F. Evaluation of the efficacy of dicyclomine hydrocloride ("Merbentyl") syrup in the treatment of infantile cloride ("Merbentyl") syrup in the treat.
colic. Curr Med Res Opin 1977;5:258-61.

18 Williams J, Watkin-Jones R. Dicyclomine: worrying symptoms associated with its use in some small babies. BMF toms associate

19 Metcalf TJ, Irons TG, Lawrence DS, Young PC. Simethicone in the treatment of infant colic: a randomized, placebocontrolled, multicenter trial. Pediatrics 1994;94:29-34.
20 Munch LK, Hoffman H, Amtoft Nielsen A. Kiropraktorbehandling af børn i første leveår. Ugeskr. Lager 1988;150: $1841-4$

21 Klougart N, Nilsson N, Jacobsen J. Infantile colic treated by chiropractors: a prospective study of 316 cases. F Manipulative Physiol Ther 1989;12:281-8.

22 Wiberg JMM, Nordsteen J, Nilsson N. The short-term effect of spinal manipulation in the treatment of infantile colic: a randomized controlled clinical trial with a blinded observer. F Manipulative Physiol Ther 1999;22:517-22.

23 Dihigo SK. New strategies for the treatment of colic: modifying the parent/infant interaction. I Pediatr Health Care 1998;12:256-62.

24 Taubman B. Clinical trial of the treatment of colic by modification of parent-infant interaction. Pediatrics $1984 ; 81$ : 998-1003.

25 Grice A, Vernon H. Basic principles in the performance of chiropractic adjusting: historical review, classification and objectives. In: Haldeman S, ed. Principles and practice of chiropractic, 2nd edn. Norwalk, USA: Appelton \& Lange, 1992:443-58.

26 Giles LG, Muller R. Chronic spinal pain syndromes: a clinical pilot trial comparing acupuncture, a nonsteroidal antiinflammatory drug, and spinal manipulation. 7 Manipulainflammatory drug, and spinal man

27 Balon J, Aker PD, Crowther ER, et al. A comparison of active and simulated chiropractic manipulation as adjunctive treatment for childhood asthma. $N$ Engl $\mathcal{F} \mathrm{Med}$ 1998;339:1013-20.

28 Sawyer CE, Evans RL, Boline PD, Branson R, Spicer A. A feasibility study of chiropractic spinal manipulation versus sham spinal manipulation for chronic otitis media with effusion in children. $\mathcal{F}$ Manipulative Physiol Ther 1999;22: $292-8$.

29 Ståhlberg MR. Infantile colic: occurrence and risk factors. Eur F Pediatr 1984;143:108-11.

30 Alvarez M, St James-Roberts I. Infant fussing and crying patterns in the first year in an urban community in Denmark. Acta Pcediatr 1996;85:463-6.

31 Canivet C, Hagander B, Jakobson I, Lanke J. Infantile colic-less common than previously estimated? Acta Pcediatr 1996;85:454-8.

\section{Dummies and acute otitis media}

Dummies (pacifiers) are popular with the parents of young children but are they harmful? Fears of serious permanent malocclusion from their use seem largely to have subsided in recent decades but other problems have been mooted, such as increases in risk of otitis media, oral thrush, and dental caries. Researchers in Finland (Marjo Niemelä and colleagues. Pediatrics 2000;106:483-8) have studied the effect on the occurrence of otitis media of counselling parents about dummy use.

Fourteen well baby clinics were paired by clinic size and social class of parents and one of each pair was randomised to intervention and the other to control. In the intervention clinics, parents were told of the possible harmful effects of dummies and advised to restrict their use after the age of 6 months to times when the child was about to go to sleep, and to stop using them altogether after the age of 10 months. There were 272 children in the intervention group and 212 controls. Use of a dummy in children aged 7-18 months fell by $20 \%$ in the intervention group and the prevalence of acute otitis media fell by almost $30 \%$.

The mechanism by which use of a dummy might increase the risk of acute otitis media is unclear. It is suggested that it may be related to pressure changes in the nasopharynx and impaired function of the eustachian tube. Doctors are often accused of finding fault with many of the things that people do. Are dummies genuinely harmful or is this another example of the philosophy of "if you like it must be bad for you"?

ARCHIVIST 